(2) Open Access Full Text Article

\title{
Immunosuppressive effects of the standardized extract of Phyllanthus amarus on cellular immune responses in Wistar-Kyoto rats
}

This article was published in the following Dove Press journal:

Drug Design, Development and Therapy

26 August 2015

Number of times this article has been viewed

\author{
Menaga Ilangkovan \\ Ibrahim Jantan \\ Mohamed Ahmed Mesaik \\ Syed Nasir Abbas Bukhari \\ Drug and Herbal Research Center, \\ Faculty of Pharmacy, Universiti \\ Kebangsaan Malaysia, Kuala Lumpur, \\ Malaysia
}

\begin{abstract}
Phyllanthus amarus (family: Euphorbiaceae) is of immense interest due to its wide spectrum of biological activities. In the present study, the standardized $80 \%$ ethanol extract of $P$. amarus was investigated for its modulatory activity on various cellular immune parameters, including chemotaxis of neutrophils, engulfment of Escherichia coli by neutrophils, and Mac-1 expression, in leukocytes isolated from treated/nontreated Wistar-Kyoto rats. The detailed cellmediated activity of $P$. amarus was also investigated, including analysis of the effects on $\mathrm{T}$ - and B-cell proliferation and $\mathrm{CD}^{+}$and $\mathrm{CD}^{+} \mathrm{T}$-cell subsets in splenic mononuclear cells, and estimation of serum cytokine production by activated T-cells. The main components of the extract, phyllanthin, hypophyllanthin, corilagin, geraniin, ellagic acid, and gallic acid were identified and quantitatively analyzed in the extracts, using validated reversed-phase high-performance liquid chromatography (HPLC) methods. N-formyl-methionyl-leucyl-phenylalanine (fMLP)induced neutrophils isolated from rats administered with the extract of $P$. amarus, at doses ranging from 100 to $400 \mathrm{mg} / \mathrm{kg}$ for 14 days, revealed a significant dose-dependent reduction in neutrophil migration $(P<0.05)$. Similar patterns of inhibition were also observed in phagocytic activity and in fMLP-induced changes in expression of $\beta_{2}$ integrin polymorphonuclear neutrophils. The results in P. amarus-treated rats also demonstrated a dose-dependent inhibition of both lipopolysaccharide-stimulated B-cell proliferation and concanavalin A-stimulated T-cell proliferation as compared with sensitized control. At a dose of $400 \mathrm{mg} / \mathrm{kg}(P<0.01)$, there was a significant decrease in the (\%) expression of $\mathrm{CD}^{+}$and $\mathrm{CD}^{+}$in splenocytes and in serum cytokines of T helper (Th1) (IL-2 and IFN- $\gamma$ ) and Th2 (IL-4). In conclusion, P. amarus showed effective immunosuppressive activities in cellular immune response, by various immune regulatory mechanisms, and may be useful for improvement of immune-related disorders.
\end{abstract}

Keywords: immunosuppression, leukocytes migration, phagocytic activity, splenic mononuclear cells, T- and B-cell proliferation

\section{Introduction}

The immune system refers to the organization of immune cells (neutrophils, macrophages, and T lymphocytes) and specialized immune molecules that have evolved to mediate resistance to infections. The coordinated interactions of these molecules and immune cells evoke an appropriate immune response. ${ }^{1-3}$ These immune responses of the human body against any nonself antigen have been divided into two interrelated subsystems, ie, innate immunity, which mediates the initial protection against infections, and adaptive immunity. The latter has been discovered to develop gradually and specifically against invading pathogens and features the presence of "memory" cell lines that enhance the response to repeated exposure to same antigen. ${ }^{4-6}$ The major cellular components of the innate immune system involve phagocytes, including neutrophils
Correspondence: Ibrahim Jantan Drug and Herbal Research Center, Faculty of Pharmacy, Universiti Kebangsaan Malaysia, Jalan Raja Muda Abdul Aziz, 50300 Kuala Lumpur, Malaysia

Tel +60162886445

Fax +6032698327

Email profibj@gmail.com 
and macrophages, which recognize and engulf microbes for intracellular killing. Many soluble proteins called cytokines, including TNF- $\alpha$, IL-1 $\beta$, IL-6, type I IFN (IFN- $\alpha$ and IFN- $\beta$ ), IFN- $\gamma$, and chemokines are also involved in defense against microbes in addition to complement system. ${ }^{7-9}$

The complement system is made up of circulating and membrane-associated proteins that play an essential role in host defense in three distinct ways: 1) facilitate opsonization of microbes by phagocytes; 2) chemotaxis of leukocyte to the site of complement activation; and 3) penetration of the microbial cell membrane by polymeric protein complex to disturb the permeability barrier, causing the death of the microbe. ${ }^{10-13}$ In contrast to the innate immune response, the adaptive immune response specifically recognizes distinct substances produced by microbes and is capable of providing a long-lasting protection. The adaptive immune response can be divided into two subgroups, humoral immunity (mediated by B lymphocytes) and cellular immunity (mediated by $\mathrm{T}$ lymphocytes). There are three different strategies utilized by the adaptive immune response in order to activate defense mechanisms against microbes: 1) blocking of the ability of microbes to cause infection in host cells, through the effect of specific antibodies; 2) enhancement of the microbicidal activities of phagocytes, with the aid of antibodies and $\mathrm{T}$ helper (Th) cells; and 3) elimination of cells infected by microbes, by cytotoxic $\mathrm{T}$ lymphocytes. ${ }^{14,15}$

Despite the complex immunological mechanisms, the effectiveness and efficiency of this system depends on dynamic interplay between antigen and a network of immunologically competent cells. This is because there are many mechanisms by which the normal immune restoration process can go awry. The failure to maintain an adequate redox balance of immune cells may lead to impaired immune response, which may pose serious threats to health. In this context, immunomodulators play an essential role in restoring immune imbalance. Clinically, immunomodulators can be classified into three main types, including immunosuppressants, immunostimulants, as well as immunoadjuvants. The benefit of immunomodulators is their regulation of the immune system, by modifying various aspects of both innate and adaptive immune responses. ${ }^{16}$

Modulation of the immune response by medicinal plants and their active components provide a potential alternative to conventional chemotherapy for a variety of immunologic diseases. In this context, the development of natural productbased drug candidates as immunomodulators has gained momentum in contemporary research studies directed toward design and discovery of drugs, as they possess fewer side effects than conventional therapies. ${ }^{16}$ Medicinal plant products have long been used as active agents of immunotherapy in traditional medicines, for the treatment of many immunological disorders. Actinidia macrosperma, Aesculus indica, Andrographis paniculata, Allium sativum, Cajanus indicus, Gymnema sylvestre, Asparagus racemosus, Baliospermum montanum, Curcuma longa, Semecarpus anacardium, Unacaria tomentosa, Tilia cordata, and Tinospora cordifolia are among the medicinal plants claimed to possess potential immunomodulatory values. ${ }^{17-39}$ In sight of this, Phyllanthus amarus (family: Euphorbiaceae) is of immense interest due to its wide spectrum of biological activities, such as anti-inflammatory, antimicrobial, antiviral (against Hepatitis B), antimutagenic, anticarcinogenic, hepatoprotective, nephroprotective, cardioprotective, and hypoglycemic..$^{40,41}$ It has been demonstrated that the medicinal properties were due to the phytochemicals possessed by $P$. amarus, including alkaloids, polyphenols, flavonoids, lignans, ellagitannins, triterpenes, sterols, and volatile oil. ${ }^{42,43}$ Recent research activities have well established the immunomodulatory properties of $P$. amarus, which provides a source for the development of agents for suppression of normal or exaggerated immune response.

Our previous studies demonstrated that standardized extracts of $P$. amarus and their major constituents (phyllanthin, hypophyllanthin, gallic acid, geranin, corilagin, and ellagic acid) potentially inhibited the in vitro chemotactic migration as well as phagocytic ability of phagocytes and suppressed the release of reactive oxygen species by granulocytes; we also isolated and identified the major bioactive compounds responsible for the immunomodulatory activity of $P$. amarus in our previous studies. ${ }^{44,45}$ The aim of the present study was to investigate the selected parameters of cellular immunity, which included migration and phagocytosis of leukocyte and Mac-1 expression, in leukocytes isolated from treated/nontreated Wistar-Kyoto rats. Further, T- and B-cell proliferation and $\mathrm{CD}^{+}$and $\mathrm{CD}^{+} \mathrm{T}$-cell subset expression in splenocytes, and serum cytokine production by activated T-cells were also investigated in Wistar-Kyoto rats. In order to further investigate the immunomodulatory properties of $P$. amarus, the cell-mediated activity was studied using a panel of antigen-specific assays for $\mathrm{T}$ - and B-cell proliferation, and $\mathrm{CD}^{+}$and $\mathrm{CD}^{+} \mathrm{T}$-cell subset analysis in splenocytes, and estimation of serum level cytokines production by activated T-cells.

\section{Materials and methods Chemical and reagents}

Lipopolysaccharide (LPS), concanavalin A (ConA), fluorescein isothiocyanate (FITC)-labeled opsonized Escherichia 
coli, 3-aminophthalhydrazide (luminol), phosphate-buffered saline (PBS) tablet, Hank's balance salt solution (HBSS), ficoll, Roswell Park Memorial Institute (RPMI)-1640, fetal bovine serum (FBS) penicillin, streptomycin, Lymphoprep ${ }^{\mathrm{TM}}$ gradient $(1,077 \mathrm{mg} / \mathrm{mL})$, trypan blue reagent, 3-(4, 5-dimethylthiazol-2-yl)-2, 5-diphenyltetrazolium bromide (MTT) reagent, and phorbol 12-myristate 13-acetate (PMA), were purchased from Sigma-Aldrich Corp ( $\mathrm{St}$ Louis, MO, USA). Sheep red blood cells (sRBCs) were obtained from Innovative Research, Inc. (Sarasota, FL, USA). FBS was obtained from PAA Laboratories (GE Healthcare, Little Chalfont, UK). Pharm Lyse ${ }^{\mathrm{TM}}$ lysing solution, FITC-conjugated anti-mouse $\mathrm{CD}$ 8, phycoerythrin (PE)-conjugated CD4, allophycocyanin (APC)-conjugated CD11b, FITC-conjugated CD18, and IgG-FITC were obtained from BD Biosciences (Franklin Lakes, NJ, USA). CytoSelect 24-well cell migration assay kits were obtained from Cell Biolabs, Inc. (San Diego, CA, USA). Cyclophosphamide, ${ }^{3} \mathrm{H}$-thymidine $(0.5 \mu \mathrm{Ci} /$ well $)$, and scintillation cocktail (Ultima Gold MV) were purchased from Perkin Elmer, Inc. (Waltham, MA, MA, USA). Radioactivity was measured using a Tri-Carb 3110 TR Perkin Elmer Liquid Scintillation Counter (Perkin Elmer, Inc.). Chemiluminescence measurements were carried out on a Luminoskan ${ }^{\mathrm{TM}}$ Ascent luminometer (Thermo Fisher Scientific, Waltham, MA, USA). Fluorescence reading was performed using Victor 2 plate reader (Perkin Elmer, Inc.). Enzyme-linked immunosorbent assay (ELISA) was performed using ProcartaPlex rat immunoassay kit (eBioscience, San Diego, CA, USA) and measured using a Luminex instrument from Bio-Rad Laboratories (Hercules, CA, USA). A microplate reader was obtained from Thermo Fisher Scientific. Hematoxylin and xylene for staining were obtained from BDH (Merck KGaA, Darmstadt, Germany). Phyllanthin and hypophyllanthin were isolated based on methods described in a previous study, with purity $>98 \%,{ }^{45}$ whereas gallic acid, ellagic acid, corilagin, and geraniin (purity $>98 \%$ ) were purchased from ChromaDex (Irvine, CA, USA). Methanol (high-performance liquid chromatography [HPLC] grade), acetonitrile (HPLC grade), and trifluoroacetic acid (analytical grade [AR]) grade were obtained from Merck KGaA. A Phagotest kit was obtained from Glycotope Technology (Berlin, Germany). The flow cytometry BDFACS Canto II equipped with $488 \mathrm{~nm}$ argon-ion laser was used (BD Biosciences). $\mathrm{A} \mathrm{CO}_{2}$ incubator (Shel Lab; Sheldon Manufacturing, Inc., Cornelius, OR, USA), light microscope, and HPLC device (Waters 2998; Leitz Wetzlar, Wetzlar, Germany) were also used in the study.
Plant material and preparation of extracts The whole plants of $P$. amarus were obtained from Marang, Kuala Terengganu, Malaysia. The plants were authenticated by Dr Abdul Latif Mohamad of the Faculty of Science and Technology, Universiti Kebangsaan Malaysia (UKM), and voucher specimens ( $P$. amarus UKMB 30078) were deposited at the Herbarium of UKM, Bangi, Malaysia. The collection of plant samples did not involve endangered or protected species, and the study was carried out at the Drug and Herbal Research Center, Faculty of Pharmacy, UKM. Whole plants of P. amarus $(1 \mathrm{~kg})$ were ground and extracted with $80 \% \mathrm{EtOH}(3 \times 3 \mathrm{~L})$ at room temperature for 72 hours, then filtered through Whatman ${ }^{\circledR}$ Grade1 filter paper (Sigma-Aldrich Corp). The filtrate was collected, and excess solvent was evaporated under reduced pressure using a rotary evaporator at temperature between $55^{\circ} \mathrm{C}$ and $60^{\circ} \mathrm{C}$. The yield of extracts obtained was $108 \mathrm{~g}(10.8 \% \mathrm{w} / \mathrm{w})$. The extract was resuspended in $5 \%$ Tween $^{\circledR} 20$ solution before being orally (PO) administered to rats.

\section{HPLC analysis of $80 \%$ ethanol extract of $P$. amarus}

HPLC analysis and validation were carried out based on the chromatographic condition described in our previous studies. ${ }^{44,45}$ Briefly, the HPLC analysis was performed using the following conditions: reverse-phase C-18 column (250 mm $\times 4.6 \mathrm{~mm}$ ID, $5 \mathrm{~m}$, XBridge ${ }^{\mathrm{TM}}$; Waters Corporation, Milford, MA, USA), and photodiode array (PDA) detector (Waters 2998) of wavelength ranging from 205 to $270 \mathrm{~nm}$. Identification and quantification of components of the extracts and standard compounds, including gallic acid, ellagic acid, corilagin, geraniin, phyllanthin, and hypophyllanthin were performed using two different chromatographic conditions, method 1 and method 2, as described in our previous study ${ }^{44,45}$ For the analysis of the extracts and standard solutions of phenolic compounds (gallic acid, ellagic acid, corilagin, and geraniin), analysis was performed using method 1, with corilagin as an external standard. The identification of each compound was carried out by comparing the retention times and ultraviolet-visible (UV-Vis) spectra of the peaks with those of the standard compounds. Identification and quantification of the lignans (phyllanthin and hypophyllanthin) were carried out based on the chromatographic conditions described in method 2. The validation of HPLC for the standardization of the extract was carried out by determination of linearity, precision, and limits of quantification (LOQ) and detection (LOD). 


\section{Animals}

All procedures in animal studies were conducted under a protocol approved by the UKM Animal Ethics Committee. During the experiment, animals were kept in faculty premises with the observance of ample conditions.

\section{Acute oral toxicity}

The acute oral toxicity of $80 \%$ ethanol extracts of P. amarus was investigated in Wistar-Kyoto rats of either sex (three male and three female rats, age ranging from 6 to 8 weeks and body weight ranging from 300-320 g) using the guidelines provided by Organisation of Economic Co-Operation and Development (Guideline 423). ${ }^{46}$ Each rat received a single dose of $80 \%$ ethanol extract of $P$. amarus (dose ranging from 100 to $500 \mathrm{mg} / \mathrm{kg}$ ) for 14 days. The weight of the rats was measured daily, and the rats were also observed for changes in their general behavior as well as physiological abnormalities.

\section{Experimental design}

The experimental material comprised 36 adult male WistarKyoto rats of inbred strains (6-8 week old), with average body weight ranging from $300-320 \mathrm{~g}$. These rats were obtained from University of Science Malaysia, Kelantan, Malaysia and had been used for cellular immunity studies. Animals were acclimatized for at least 1 week prior to being placed on study. The animals were initially divided into six groups. The negative control group (group 1) received a regular diet, and the vehicle control group (group 2) received 5\% Tween 20 solution. Animals in the positive control group (group 3) received cyclophosphamide, a known immunosuppressant, PO at a dose of $100 \mathrm{mg} / \mathrm{kg}$ body weight of the animal. The animals in the experimental groups (groups 4-6) received $80 \%$ P. amarus extract at doses of 100,200 , and $400 \mathrm{mg} / \mathrm{kg}$ body weight, respectively, over a period of 14 days. Blood samples were collected on day 14 , by retroorbital puncture, to evaluate the effects of $P$. amarus on the phagocytic activity of neutrophils. The rats were then immunized with sRBC, a T-cell-dependent antigen, on day 15. The blood samples were collected again on day 21 prior to the analysis for $\mathrm{T}$ - and B-cell proliferation, $\mathrm{CD} 4^{+}$and $\mathrm{CD} 8^{+}$expression in T-cell subsets in splenocytes, and estimation of serum level cytokine production by activated T-cells. The doses of positive control and the extract used in this study were selected based on previous studies. ${ }^{44,45}$ P. amarus was extracted in $80 \%$ ethanol in this study, as the highest amount of lignan, phenolic, and flavonoid compounds can be retrieved at $80 \%$ ethanol concentration. ${ }^{47-49}$ These compounds were believed to be the main contributors to the immunosuppressive properties of $P$. amarus, and our previous study demonstrated the major contribution of phenolic compounds to immunosuppressive activity. Animal rooms were maintained between $18^{\circ} \mathrm{C}$ and $26^{\circ} \mathrm{C}$ with a relative humidity of $40 \%-70 \%$ and a 12-hour light/dark cycle. The animals were maintained on a standard pellet diet and tap water access was provided ad libitum. Body weights were obtained regularly, and dosing volumes were adjusted accordingly. All animals were dosed once daily for 14 days PO, by gavage, to evaluate the toxicity of extracts/drug on the body weight and liver of rats.

\section{Isolation of neutrophils from whole rat blood}

The isolation of neutrophils was from whole rat blood, which was drawn from treated rats before immunization. This was performed using a modified Histopaque ${ }^{\circledR}$ gradient technique as described by Kumar et al. ${ }^{50}$ Briefly, $5 \mathrm{~mL}$ of Lymphoprep gradient $(1,077 \mathrm{mg} / \mathrm{mL})$ was placed into a $10 \mathrm{~mL}$ Falcon ${ }^{\circledR}$, tube and equal volume of whole rat blood was carefully layered on the gradient without any break to the gradient. The Falcon tube, containing two-step gradients of Lymphoprep and blood was centrifuged at $400 \times g$ for 45 minutes. The neutrophils and erythrocytes sedimented through the lymphoprep layer during centrifugation. The erythrocytes were then lysed using Pharm Lyse lysing solution. At the end of incubation, the falcon tube was centrifuged at $200 \times g$ for 5 minutes. The supernatant was aspirated carefully without disturbing the pellet and resuspended in PBS. The viability of cells was checked with trypan blue exclusion assay.

\section{Cell migration assay}

The effect on neutrophils migration was quantitatively access by using CytoSelect 24-well Cell Migration Assay kits (Cell Biolabs, Inc.). The neutrophils were isolated from nonimmunized rats. The cell suspension, containing $1.5 \times 10^{6}$ cells in $300 \mu \mathrm{L}$ serum-free media was added to the upper chamber (consisting of a polycarbonate membrane insert, with $3 \mu \mathrm{m}$ pore-sized filters) of a 24-well tissue culture plate, while RPMI $(500 \mu \mathrm{L})$ media containing chemotactic stimulant, $\mathrm{N}$-formyl-methionyl-leucyl-phenylalanine (fMLP) $\left(10^{-8} \mathrm{M}\right)$, was added to the lower chambers of the 24 -well plate. The cell suspension was left in the inside of each insert to migrate for 2.5 hours at $37^{\circ} \mathrm{C}$ and $10 \% \mathrm{CO}_{2}$. The migratory cells passed through polycarbonate membrane and adhered to the bottom side. The insert was then transferred to a new well containing cell detachment solution and incubated at $37^{\circ} \mathrm{C}$ and $10 \% \mathrm{CO}_{2}$ for 30 minutes to dislodge the cells. Lysis buffer/CyQuant ${ }^{\mathbb{B}}$ 
GR dye solution was added to stain the dislodged cells. The number of cells migrating to lower chambers was determined by fluorescence, per manufacturer's instructions, on a Victor 2 plate reader (Perkin Elmer, Inc.).

\section{Ib and CDI8 integrin expression on leukocytes}

The CD11b/CD18 integrin expression assay was performed using a modified method of Jantan et al. ${ }^{44}$ Aliquots $(100 \mu \mathrm{L})$ of neutrophils isolated from whole blood of nonsensitized rats were stimulated with fMLP $(1 \mu \mathrm{M})$ for 90 minutes at $37^{\circ} \mathrm{C}$ in a $\mathrm{CO}_{2}$ incubator. Then, all the tubes were simultaneously transferred to an ice bath to stop the reaction. Subsequently, $10 \mu \mathrm{L}$ of CD11b-PE, CD18-FITC, or IgG-FITC (negative control) was added to the mixture. All the tubes were incubated for 60 minutes on ice. Pharm Lyse lysing solution was added into each tube and incubated in dark for 20 minutes to lyse the red blood cells. The tubes were centrifuged at $250 \times g$ for 5 minutes at $4^{\circ} \mathrm{C}$, then the supernatant was removed from the tubes, and cells were washed with PBS (three times). PBS $(0.5 \mathrm{~mL})$ was added to each tube, and the expression of celladhesion molecules was determined by flow cytometry. The specific mean fluorescence intensity for cells stained by each antibody was reported as percentage of CD11b and CD18 expression. For each sample, 10,000 cells were analyzed.

\section{Phagocytic assay}

The neutrophils were isolated from the whole blood collected from nonsensitized rats through the retroorbital method. The effect of the leukocytes on phagocytic activity was determined by a commercially available kit. The assay was carried out according to the protocol given by the manufacturer. Briefly, $100 \mu \mathrm{L}$ neutrophil cell suspension was incubated with $20 \mu \mathrm{L}$ FITC-labeled E. coli in a closed shaking water bath at $37^{\circ} \mathrm{C}$ for 10 minutes. Phagocytosis was quenched by adding ice-cold quenching solution to the mixture at the end of the incubation period. After a final wash, the cells were resuspended in DNA-staining solution to exclude aggregation artifacts of bacteria or cells, and analyzed by flow cytometry. The phagocytic ability was evaluated in leukocytes. Live populations were gated by the software program in the scatter diagram (FCS versus SSC). Phagocytic activity was determined based on the percentage of phagocytizing neutrophils.

\section{Antigenic stimulus}

Animals were put into six groups, with six rats in each group. The animals in all groups were immunized with sRBCs obtained from Innovative Research, Inc. The antigen was prepared by washing the sRBCs three times with cold PBS. The washed sRBCs were then resuspended in PBS prior to immunization. sRBC immunization was performed by injecting $5.0 \times 10^{8} \mathrm{sRBCs} / \mathrm{mL}$ intraperitoneally (IP) in $200 \mu \mathrm{L}$, 2 weeks after each group was treated with either $P$. amarus (100, 200, or $400 \mathrm{mg} / \mathrm{kg}$ PO, daily), cyclophosphamide (100 mg/kg, PO, daily), or vehicle.

\section{Spleen cell suspension preparation}

The spleen cell suspension was used in the investigation of the effects of $P$. amarus extract on lymphocyte proliferation and lymphocyte phenotyping. The spleen was aseptically removed from rats that were immunized with $5.0 \times 10^{8}$ sRBCs/mL IP 2 weeks after each group was treated with either P. amarus (100, 200, or $400 \mathrm{mg} / \mathrm{kg}$ PO, daily, based on preliminary investigations), cyclophosphamide (100 mg/ $\mathrm{kg}$ PO, daily), or vehicle. The splenocyte suspension was performed using minor modification of the method outlined by Wang et al. ${ }^{51}$ The sacrificed animal was placed on a clean dissection board and rinsed with $70 \%$ alcohol. The abdominal cavity was incised to remove the spleen. The tissue was placed into a labeled conical tube containing PBS. The spleen was then sliced into small pieces, which were then placed onto a nylon cell strainer of the size $70 \mu \mathrm{m}$ obtained from BD Biosciences. The excised spleen was pressed through the strainer using the plunger at the end of a syringe. The cells were washed through the strainer with excess PBS. The cell suspension was then centrifuged at $300 \times g$ for 5 minutes. The supernatant was aspirated, and the pellet was resuspended in $2 \mathrm{~mL}$ prewarmed (at $37^{\circ} \mathrm{C}$ ) Pharm Lyse lysing solution to lyse the RBCs. The cells were lysed at room temperature for 3 minutes at $37^{\circ} \mathrm{C}$. The cells were then centrifuged at $400 \times g$ for 5 minutes. The supernatant was discarded, and the pellet was resuspended in $1 \mathrm{~mL}$ RPMI-1640 complete medium with $10 \%$ (v/v) FBS, 100,000 units/L of penicillin, and $0.1 \mathrm{mg} / \mathrm{mL}$ of streptomycin. The viability of cells was checked with trypan blue exclusion assay.

\section{T and B lymphocyte proliferation assay}

Assays of lymphocyte proliferation were performed using ${ }^{3} \mathrm{H}$-thymidine as described by Colić et al. ${ }^{52}$ Briefly, the splenocyte suspension (containing $\left(4 \times 10^{5}\right.$ cells $\left./ \mathrm{mL}\right)$, in RPMI-1640 medium with 10\% (v/v) FBS, 100,000 units/L of penicillin, and $0.1 \mathrm{mg} / \mathrm{mL}$ of streptomycin was preincubated in 96-well plates $(200 \mu \mathrm{L} /$ well $)$ in the presence or absence of mitogens (ConA or LPS at concentration of $5 \mu \mathrm{g} / \mathrm{mL}$ and $10 \mu \mathrm{g} / \mathrm{mL}$, respectively) at $37^{\circ} \mathrm{C}$ for 72 hours in a humid 
saturated atmosphere containing 5\% $\mathrm{CO}_{2}$. After 48 hours, the cultures were incubated with ${ }^{3} \mathrm{H}$-thymidine $(0.5 \mu \mathrm{Ci}$ / well) for 24 hours. After the incubation period, the cells were harvested on glass fiber filters, using a Nunc cell harvester, and the thymidine incorporation was determined by a liquid scintillation counter (counts per minutes [cpm]), by adding $5 \mathrm{~mL}$ of scintillation fluid. The results were expressed as the stimulation index (SI), which was calculated using the following formula:

$$
\mathrm{SI}=\frac{\text { Average } \mathrm{cpm} \text { with stimulation }}{\text { Average cpm without stimulation (medium only) }}
$$

\section{T lymphocyte phenotyping by flow cytometric analysis}

The T-cell subset isolated from splenocytes in treated rats was determined by a modified method described by Gupta et $\mathrm{al}^{53}$ using FACScan analysis of $\mathrm{CD} 4^{+}$and $\mathrm{CD} 8^{+}$molecules obtained from BD Biosciences Pharmingen (San Jose, CA, USA). Briefly, splenocytes $\left(1 \times 10^{6}\right.$ cells $\left./ \mathrm{mL}\right)$ were incubated directly with the $10 \mu \mathrm{L}$ FITC-conjugated anti-mouse CD8 and $\mathrm{PE}$-conjugated antibodies (which were conjugated with different fluorochromes and directed against CD4 and CD8) for 30 minutes after the lysis of dark RBCs by Pharm Lyse lysing solution. Acquisition and analysis were performed using multicolor flow cytometry using Cell Quest Pro Software. The results were expressed in percentage of $\mathrm{CD}^{+}$ and $\mathrm{CD}^{+}$expression.

\section{Measurement of Thl/Th2 cytokines}

Blood was collected from rats killed by cervical dislocation, under sterile conditions. The serum was separated from whole blood by centrifuging it at $1,000 \times g$ and $4^{\circ} \mathrm{C}$ for 20 minutes. The serum levels of IL-2, IL-4, and IFN- $\gamma$ were quantitatively determined using the 5-plex magnetic beads-based ProcartaPlex rat immunoassay kit (eBioscience). The test was performed, and the analysis was carried out according to the manufacturer's instructions. Briefly, antibody-coated magnetic beads were captured by adding $50 \mu \mathrm{L}$ of beads to each well of a 96-well plate, which was inserted into the magnetic plate washer. Serum samples $(25 \mu \mathrm{L})$ were mixed with captured antibody-coated magnetic beads. Subsequently, $25 \mu \mathrm{L}$ of assay buffer was added to each well and incubated for 2 hours on a magnetic shaker at room temperature in a dark room. Following incubation, the beads were washed using wash buffer, three times. After washing, $25 \mu \mathrm{L}$ of detection antibody were mixed into each well, and the samples were further incubated 30 minutes at room temperature in a dark room. After incubation, the washing steps were repeated as mentioned above. Then, $50 \mu \mathrm{L}$ of streptavidin PE solution was added into each well and further incubated for 30 minutes at room temperature. After incubation, the washing steps were repeated as mentioned above. Reading buffer $(120 \mu \mathrm{L})$ was added to each well, and the cytokines concentration was determined by reading the plate on a Luminex instrument.

\section{Cell viability assay}

The in vivo cytotoxicity of $P$. amarus in splenocytes obtained from sRBC-immunized rats was determined using MTT assay. Briefly, the isolated splenocytes were seeded $\left(2 \times 10^{5}\right.$ cells/well), in triplicate, in a 96-well culture plate. Suboptimal concentrations of the stimulants ConA $(5 \mu \mathrm{g} / \mathrm{mL})$ and LPS $(10 \mu \mathrm{g} / \mathrm{mL})$ were added to each well separately for enumeration of T-cells and B-cells, respectively. The plates were incubated at $37^{\circ} \mathrm{C}$ in a humidified atmosphere of $5 \% \mathrm{CO}_{2}$ for 72 hours. After incubation, cell viability was determined by MTT assay, based on the method described by Chauhan et al. ${ }^{54}$ Absorbance was measured using a microplate reader at $570 \mathrm{~nm}$.

\section{Statistical analysis}

The results were subjected to statistical analysis using a oneway analysis of variance (ANOVA) with post-Dunnett's test (to compare test samples with the control), using GraphPad Prism 5 software (GraphPad Software, Inc., La Jolla, CA, USA), and were expressed as the mean \pm standard error of the mean of at least six experimental values. $P<0.001$, $P<0.01$, and $P<0.05$ were considered to be statistically significant.

\section{Results HPLC analysis}

The chromatograms of reversed-phase HPLC of the extract of $P$. amarus showed six major compounds (gallic acid, ellagic acid, geraniin, corilagin, phyllanthin, and hypophyllanthin). The chromatograms of the reversed-phase HPLC column of the $80 \%$ ethanol extracts of $P$. amarus (using method 1 ) showed four major peaks of gallic acid, geraniin, corilagin, and ellagic acid, corresponding to retention times at 8.187 \pm 0.0072 , $23.709 \pm 0.078,26.519 \pm 0.370$, and $33.595 \pm 0.138$ minutes, respectively (Figure 1A). The HPLC chromatogram obtained from method 2 showed sharp peaks for phyllanthin and hypophyllanthin at the retention times of $27.235 \pm 0.095$ and $28.081 \pm 0.117$ minutes, respectively (Figure 1B). Quantitative determination of the major compounds by HPLC indicated 

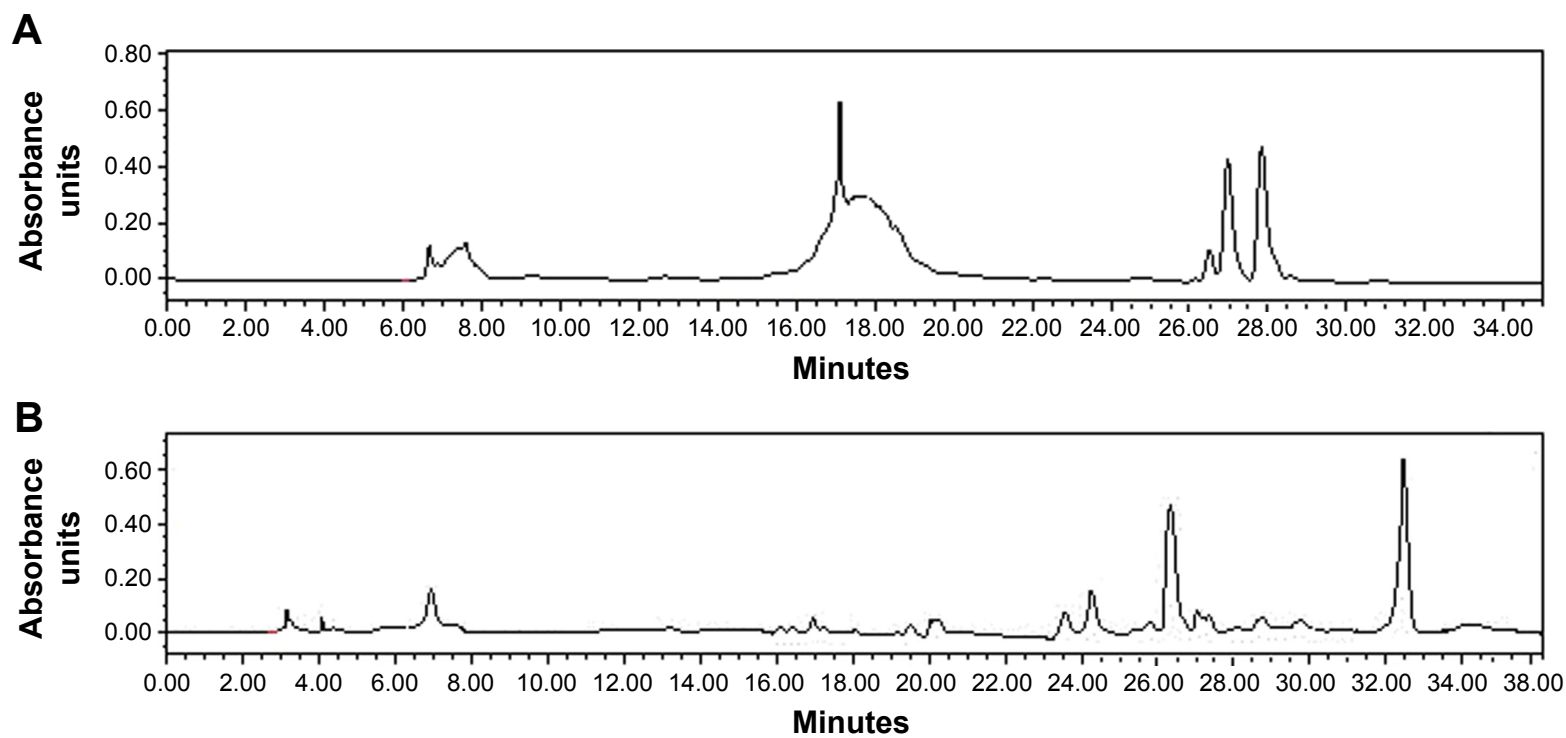

Figure I Representative HPLC chromatograms of (A) Phyllanthus amarus for identification of phyllanthin and hypophyllanthin at RT and 27.279 and 28.05I, respectively; and of (B) P. amarus for identification and quantification of gallic acid at RT and 7.89I minutes, geraniin at RT and 23.764 minutes, corilagin at RT and 26.416 minutes, ellagic acid at RT and 33.42 I minutes, with an unidentified peak at RT (23.860 minutes).

Abbreviations: HPLC, high-performance liquid chromatography; RT, room temperature.

that ellagic acid $(605.19 \pm 0.23 \mu \mathrm{g} / \mathrm{mL})$ was the most abundant followed by corilagin $(318.14 \pm 0.46 \mu \mathrm{g} / \mathrm{mL})$, geraniin $(168.19 \pm 1.12 \mu \mathrm{g} / \mathrm{mL})$, gallic acid $(181.17 \pm 0.55 \mu \mathrm{g} / \mathrm{mL})$, hypophyllanthin $(108.11 \pm 0.48 \mu \mathrm{g} / \mathrm{mL})$, and phyllanthin $(99.49 \pm 0.078 \mu \mathrm{g} / \mathrm{mL})$. The calibration curve plotted for the standard solution of corilagin over the concentration range of $62.5-500 \mu \mathrm{g} / \mathrm{mL}$ showed a correlation coefficient $\left(r^{2}\right)$ of 0.996 . The reproducibility of the results was confirmed by the relative standard deviations (\% RSDs) of the mean area under the peak and mean retention time, which were $1.814 \%$ and $0.932 \%$, respectively, for the interday assay, whereas the $\%$ RSD values for the intra-assay precision of the peak area and retention time were $3.68 \%$ and $1.092 \%$, respectively. The LOD and LOQ of corilagin were found to be 1.863 and $5.651 \mathrm{ng} / \mathrm{mL}$, respectively. The calibration curves plotted were linear over the concentration range of $31.25-250 \mu \mathrm{g} / \mathrm{mL}$, with $r^{2}$ of 0.9970 and 0.9973 for phyllanthin and hypophyllanthin, respectively. Reproducibility of the results was demonstrated, where the $\%$ RSD values for interday assay precision of the peak area and retention time were $1.63 \%$ and $0.216 \%$, respectively, for hypophyllanthin and $8.173 \%$ and $0.136 \%$, respectively, for phyllanthin, whereas the \% RSD values for intra-assay precision of the peak area and retention time were $6.172 \%$ and $0.858 \%$, respectively, for hypophyllanthin and $7.252 \%$ and $0.321 \%$, respectively, for phyllanthin. The LOD and LOQ of hypophyllanthin were found to be 2.331 and $7.0712 \mathrm{ng} / \mathrm{mL}$, respectively, while for phyllanthin were found to be 5.481 and $16.621 \mathrm{ng} / \mathrm{mL}$, respectively.

\section{Acute oral toxicity}

The animals that were treated with $80 \%$ ethanol extract of $P$. amarus (doses ranging from 100 to $500 \mathrm{mg} / \mathrm{kg}$ ) did not possess any abnormal behavior and mortality. This indicates that the concentrations of the extract used were safe for this study.

\section{Cell viability}

The study of cell viability is essential in order to assess toxicity of the target drug being investigated. In the present study, the ex vivo and in vivo cell cytotoxicity assays were performed in order to investigate the toxicity effect of $P$. amarus extract in immune cells isolated from treated rats. The results obtained denotes that $P$. amarus did not exert any cytotoxic effects in immune cells, and more than $90 \%$ cell viability was recorded in rats that were treated with P. amarus extracts at doses ranging from 100 to $400 \mathrm{mg} / \mathrm{kg}$.

\section{Cell migration assay}

To study the effect of $P$. amarus on a leukocyte migration assay, neutrophils were purified from the blood of rats that were pretreated with or without the $80 \%$ ethanol extract of $P$. amarus. fMLP induced neutrophil chemotaxis under the control conditions, and pretreatment of the rats with extract of $P$. amarus at doses ranging from 100 to $400 \mathrm{mg} / \mathrm{kg}$ revealed that the rats administered plant extracts of different doses had dose-dependent reduction in ex vivo neutrophil migration, as shown in Figure 2. The highest level of inhibitory 


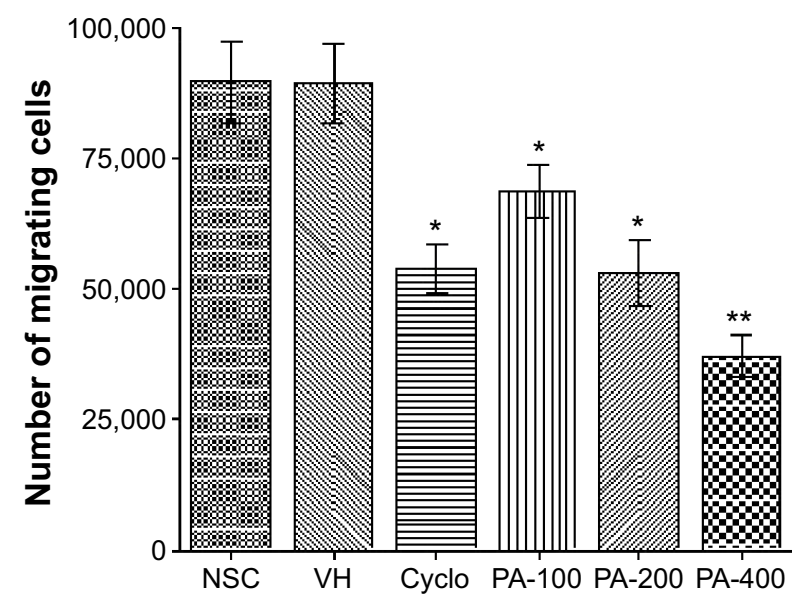

Figure 2 Graph of the effect of Phyllanthus amarus $(100,200$, and $400 \mathrm{mg} / \mathrm{kg}$ ) on the chemotaxis of neutrophils isolated from experimental animals.

Notes: Results are represented as mean \pm SEM, with $n=6$ in each group. $* * P<0.01$; $* P<0.05$. The statistical tests employed were ANOVA, followed by post-Dunnett's test.

Abbreviations: ANOVA, analysis of variance; Cyclo, cyclophosphamide; NSC, nonsensitized control; PA, Phyllanthus amarus; SEM, standard error of the mean; VH, vehicle-treated group.

activity of neutrophil migration was observed at the dose of $400 \mathrm{mg} / \mathrm{kg}(P<0.01)$, which was comparable to that of the immunosuppressive control drug (cyclophosphamide) used in this study.

\section{Measurement of Mac-I regulation by flow cytometry}

The adhesion and extravasation of neutrophils have been shown to be mainly dependent on upregulation of Mac-1 (CD11b/CD18). The Mac-1 glycoprotein is generally stored within specialized granules of resting neutrophils and will be translocated to the surface of neutrophils upon activation. ${ }^{55}$ In this study, the potential effect of $P$. amarus on the regulation of CD1 $1 \mathrm{~b}$ and CD18 expression (as a percentage) were investigated. The percentage of CD11b and CD18 expression in neutrophils isolated from extract-treated rats, which was measured using flow cytometry, depicted that the $P$. amarus treatment during 14 days with three selected doses potentially inhibited Mac-1 expression in neutrophils compared with control group. Significant level of inhibitory activity was observed at higher doses (200 and $400 \mathrm{mg} / \mathrm{kg}$ ). A statistical summary of the potential effect of $P$. amarus on the upregulation of Mac-1 is illustrated in Table 1 and Figure 3.

\section{Phagocytic activity of neutrophils in treated rats}

Phagocytosis is a process that involves binding and engulfment of invading pathogens by neutrophils. The administration of
Table I Evaluation of phagocytic activity (\%) of neutrophils isolated from rats that were administered extracts of Phyllanthus amarus at different doses (100, 200, and $400 \mathrm{mg} / \mathrm{kg}$ )

\begin{tabular}{lllll}
\hline Group & $\begin{array}{l}\text { Dose } \\
(\mathbf{m g} / \mathbf{k g})\end{array}$ & $\begin{array}{l}\text { Phagocytic } \\
\text { activity (\%) }\end{array}$ & CDI8 (\%) & CDIlb (\%) \\
\hline NSC & & $71.15 \pm 3.52$ & $44.19 \pm 1.09$ & $32.91 \pm 2.01$ \\
VH & & $70.87 \pm 2.35$ & $46.63 \pm 1.86$ & $34.79 \pm 1.17$ \\
PA & 100 & $64.36 \pm 2.27 * *$ & $30.19 \pm 1.04 * *$ & $20.14 \pm 2.38 * *$ \\
PA & 200 & $62.51 \pm 2.93 * *$ & $25.51 \pm 2.49 * *$ & $17.05 \pm 3.02 * *$ \\
PA & 400 & $59.69 \pm 2.38^{* *}$ & $20.17 \pm 1.83^{* *}$ & $15.51 \pm 3.01 * *$ \\
Cyclo & 200 & $47.78 \pm 3.15^{* *}$ & $21.13 \pm 2.82^{* *}$ & $18.19 \pm 2.14^{* *}$ \\
\hline
\end{tabular}

Notes: The values are expressed as the mean \pm SEM, with $n=6$ in each group. $* * P<0.0$ I. The statistical tests employed were ANOVA, followed by post-Dunnett's test.

Abbreviations: ANOVA, analysis of variance; Cyclo, cyclophosphamide; NSC, nonsensitized control; PA, Phyllanthus amarus; SEM, standard error of the mean; VH, vehicle-treated group.

the extracts of $P$. amarus to rats resulted in significant $(P<0.01)$ decrease in the engulfment of $E$. coli by the neutrophils isolated from extract-treated rats in comparison with the control group (Table 1, Figure 4). The results obtained showed that the extract produced a dose-dependent increase in the inhibitory action of phagocytosis, while the highest inhibitory activity (\%) was observed at the dose of $400 \mathrm{mg} / \mathrm{kg}$ and was comparable to the activity shown by the control used in this study (cyclophosphamide).

\section{Splenocyte proliferation}

The modulatory effects of $80 \%$ ethanol extract of $P$. amarus on splenic lymphocyte proliferation in response to induction of mitogen were investigated. The results revealed that the extracts of $P$. amarus potentially inhibited the activity of ConA-induced T-cell proliferation and LPS-induced B-cell proliferation, in dose-dependent manner. This was comparable with the control group, with the most and highly significant inhibition at the dose of $400 \mathrm{mg} / \mathrm{kg}$, as shown in Table 2.

\section{Lymphocyte phenotyping}

The splenic lymphocytes of treated rats were characterized based on the expression of surface markers for Th cells $\left(\mathrm{CD}^{+}\right)$and $\mathrm{T}$ suppressor cells $\left(\mathrm{CD}^{+}\right)$, using flow cytometry. The results obtained from flow cytometry revealed that the extracts of $P$. amarus at graded doses produced significant and dose-dependent inhibition in the percentage of $\mathrm{CD}^{+}$and $\mathrm{CD}^{+}$expression as compared with the sensitized control. However, highly significant inhibition in the percentage of CD4 expression was produced at doses of 200 and $400 \mathrm{mg} / \mathrm{kg}$ as compared with the sensitized control (Table 2, Figure 5). 

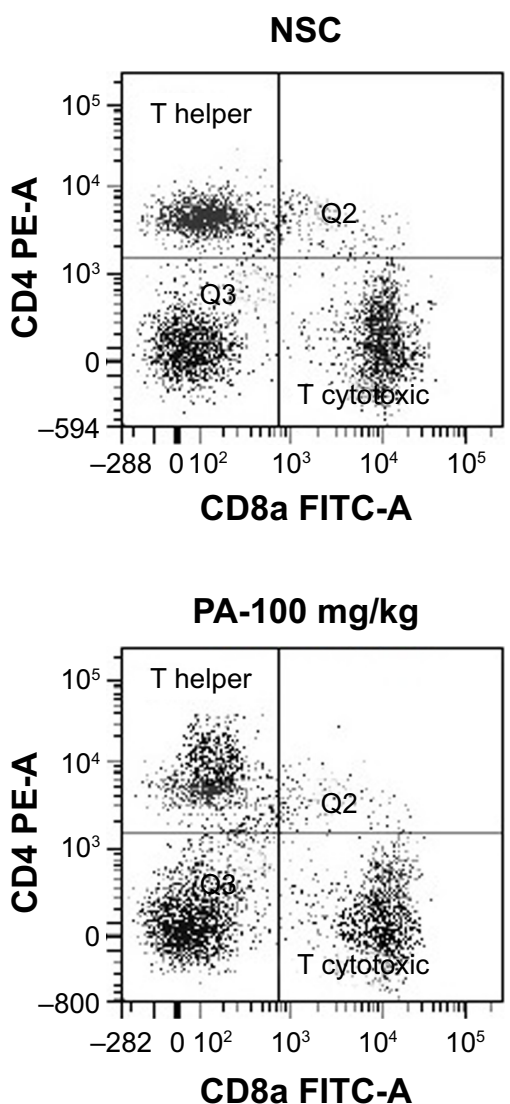
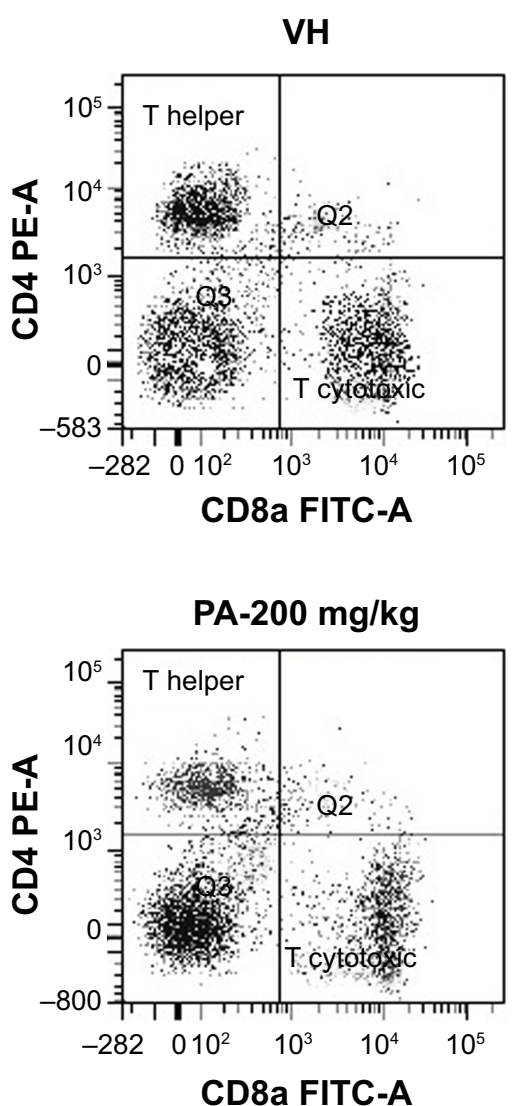

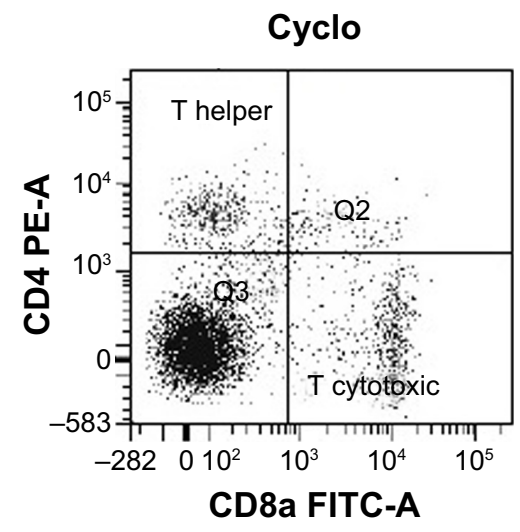

PA-400 $\mathrm{mg} / \mathrm{kg}$

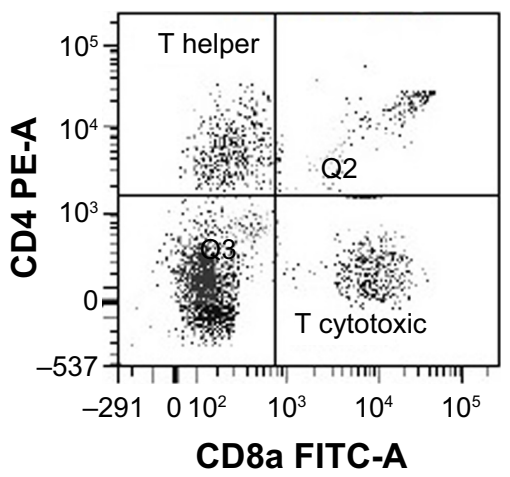

Figure 3 Flow cytometric evaluation of the effect of Phyllanthus amarus (100, 200, and $400 \mathrm{mg} / \mathrm{kg})$ on CDI8 and CDI Ib in neutrophils isolated from experimental animals. Abbreviations: Cyclo, cyclophosphamide; FITC, fluorescein isothiocyanate; NSC, nonsensitized control; PA, Phyllanthus amarus; VH, vehicle-treated group.

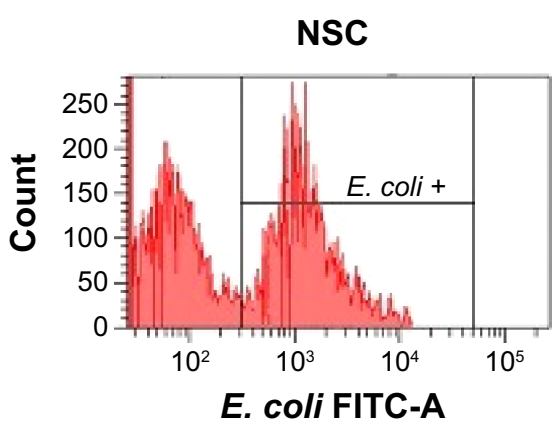

PA-100

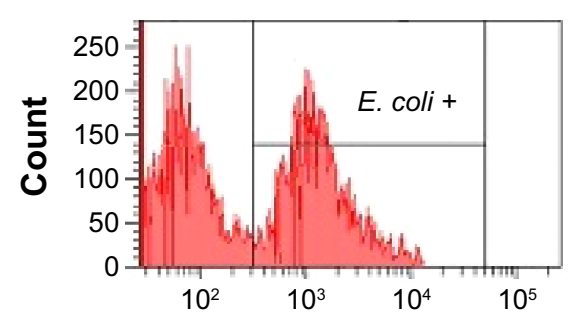

E. coli FITC-A

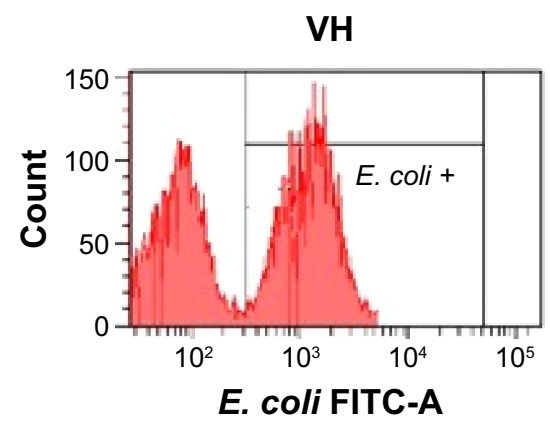

PA-200

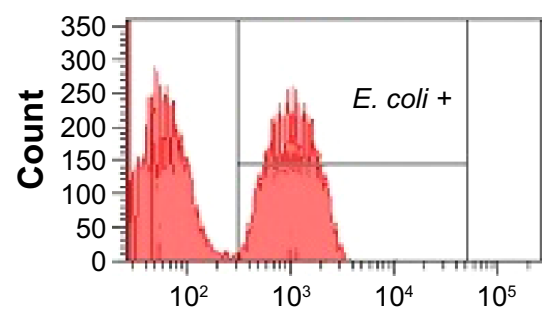

E. coli FITC-A

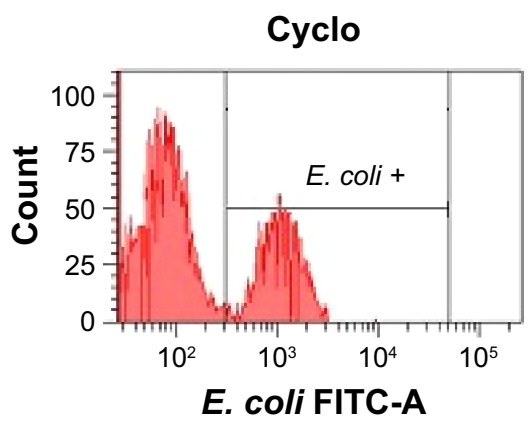

PA-400

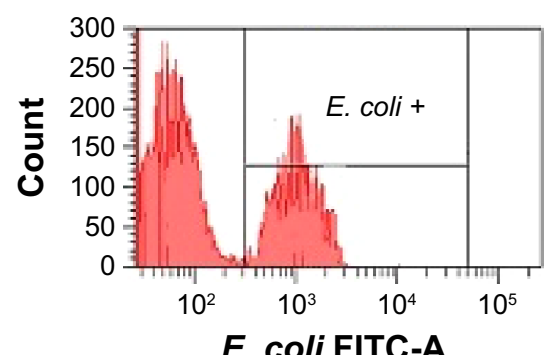

Figure 4 Flow cytometric evaluation of the effect of Phyllanthus amarus (100, 200, and $400 \mathrm{mg} / \mathrm{kg}$ ) on phagocytosis of FITC-conjugated E. coli by neutrophils isolated from treated rats.

Abbreviations: Cyclo, cyclophosphamide; FITC, fluorescein isothiocyanate; NSC, nonsensitized control; PA, Phyllanthus amarus; VH, vehicle-treated group; E. coli, Escherichia coli. 
Table $2 \mathrm{CD}^{+}$and $\mathrm{CD}^{+}$expression (\%) in spleen cells, and $\mathrm{T}$ and $\mathrm{B}$ lymphocyte proliferation (SI) in rats that were administered extracts of Phyllanthus amarus at different doses $(100,200$, and $400 \mathrm{mg} / \mathrm{kg})$

\begin{tabular}{|c|c|c|c|c|c|}
\hline \multirow[t]{2}{*}{ Group } & \multirow{2}{*}{$\begin{array}{l}\text { Dose } \\
(\mathrm{mg} / \mathrm{kg})\end{array}$} & \multicolumn{2}{|c|}{ T-cell subset detection (\%) } & \multicolumn{2}{|c|}{ Lymphocyte proliferation (SI) } \\
\hline & & $\mathrm{CD4}^{+}$ & $\mathrm{CD8}^{+}$ & T-cell & B-cell \\
\hline SC & & $50.32 \pm 1.76$ & $23.34 \pm 3.25$ & $2.83 \pm 1.87$ & $1.98 \pm 2.05$ \\
\hline $\mathrm{VH}$ & & $50.14 \pm 1.64$ & $23.57 \pm 2.88$ & $2.89 \pm 1.04$ & $2.04 \pm 1.87$ \\
\hline Cyclo & 200 & $24.57 \pm 1.44 * *$ & $\mid 0.09 \pm 2.8 I^{* *}$ & $1.18 \pm 3.1^{* *}$ & $0.89 \pm 3.45 * *$ \\
\hline PA & 100 & $47.25 \pm 2.65^{*}$ & $22.73 \pm 4.65^{*}$ & $2.18 \pm 3.09 *$ & $1.6 \mathrm{I} \pm 3.52 *$ \\
\hline PA & 200 & $42.82 \pm 2.23 * *$ & $21.47 \pm 3.09 * *$ & $1.82 \pm 0.55 * *$ & $1.05 \pm 3.15 * *$ \\
\hline PA & 400 & $38.7 I \pm 2.47 * *$ & $17.69 \pm 4.56 * *$ & $0.96 \pm 0.13 * *$ & $0.74 \pm 1.07 * *$ \\
\hline
\end{tabular}

Notes: The values are expressed as mean \pm SEM, with $n=6$ in each group. $* * P<0.01$. $* P<0.05$. The statistical tests employed were ANOVA, followed by post-Dunnett's test.

Abbreviations: ANOVA, analysis of variance; Cyclo, cyclophosphamide; PA, Phyllanthus amarus; SC, sensitized control; SEM, standard error of the mean; SI, stimulation index; $\mathrm{VH}$, vehicle-treated group.

\section{The effect of $P$. amarus on serum level of} IL-4, IL-2, and IFN- $\gamma$

Th1 and Th2 are subsets of CD4+ $\mathrm{T}$ lymphocytes that play a vital role in controlling immune balance in the protection of host against pathogenic invasion. In the present study, the role of $P$. amarus extracts in the differentiation of CD4 T-cells under Th1 or Th2 polarizing conditions were investigated. PO administration of cyclophosphamide and $P$. amarus at specified doses produced a significant inhibition in secretion of both Th1 and Th2 cytokine in a dose-dependent manner, as shown in Figure 6. The inhibition of serum IL-4 $(80.97 \pm 3.58 \mathrm{pg} / \mathrm{mL})$ and IFN- $\gamma(28.68 \pm 6.53 \mathrm{pg} / \mathrm{mL})$ was significantly higher than in the sensitized control group at $400 \mathrm{mg} / \mathrm{kg}$. The production of IL-4 enables the activation and switching of B lymphocytes for IgE release that underlies allergic reactions. In addition, the serum level of IL-2, which is the essential for growth of T-cells, was significantly reduced in the extract-treated groups, especially at the highest concentration of extract (400 mg/kg) where it was comparable with that in the cyclophosphamide-treated group $(8.443 \pm 1.47 \mathrm{pg} / \mathrm{mL})$.

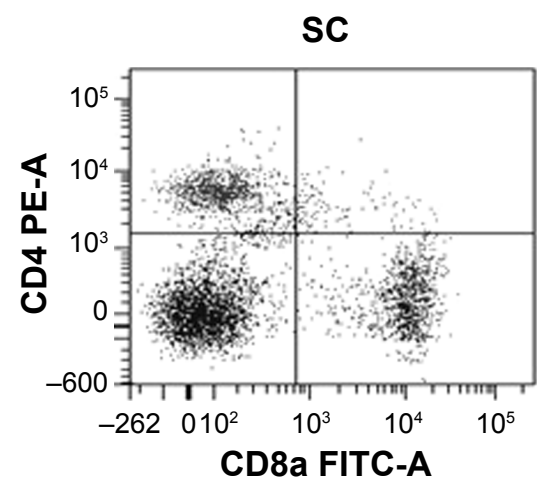

$\mathrm{PA}-100 \mathrm{mg} / \mathrm{kg}$

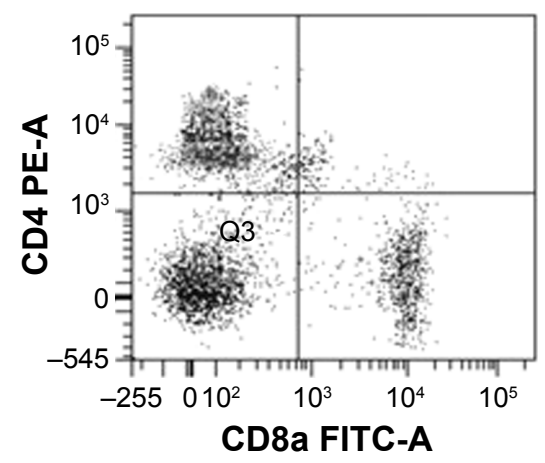

VH

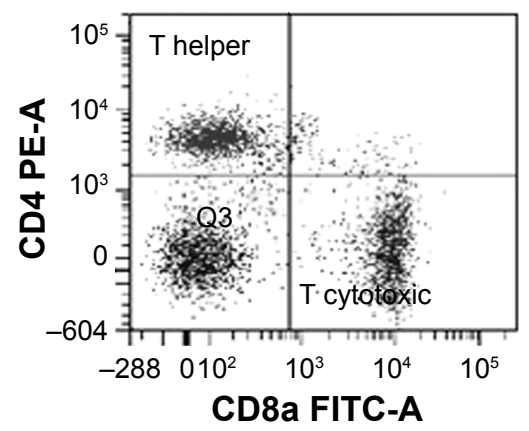

PA-200 mg/kg

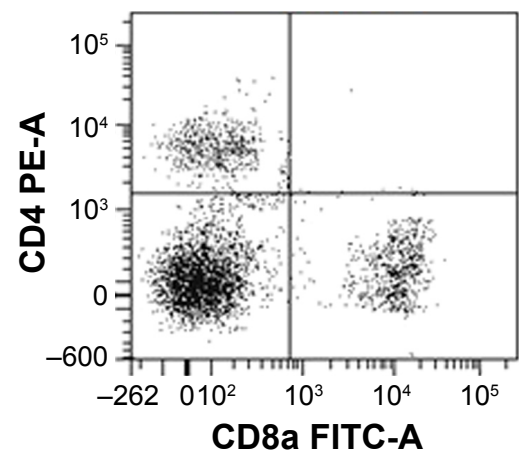

Cyclo

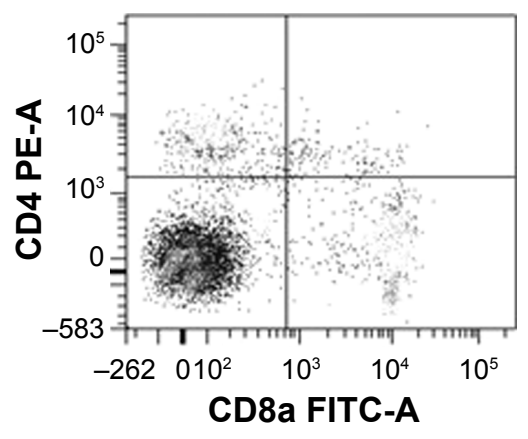

$\mathrm{PA}-400 \mathrm{mg} / \mathrm{kg}$

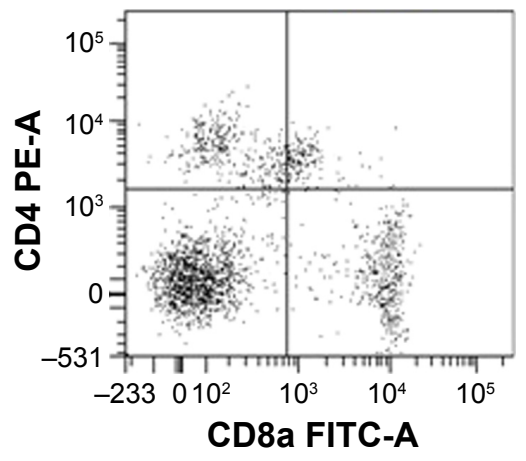

Figure 5 Flow cytometric evaluation of the effect of Phyllanthus amarus (100, 200, and $400 \mathrm{mg} / \mathrm{kg}$ ) on CD4 and CD8 in splenocytes of experimental animals. Abbreviations: Cyclo, cyclophosphamide; FITC, fluorescein isothiocyanate; PA, Phyllanthus amarus; SC, sensitized control; VH, vehicle-treated group. 
A

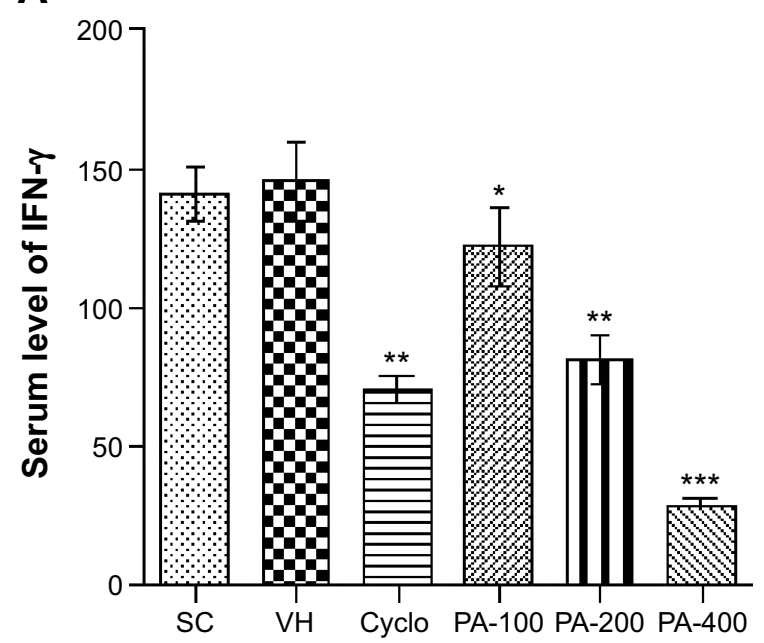

B

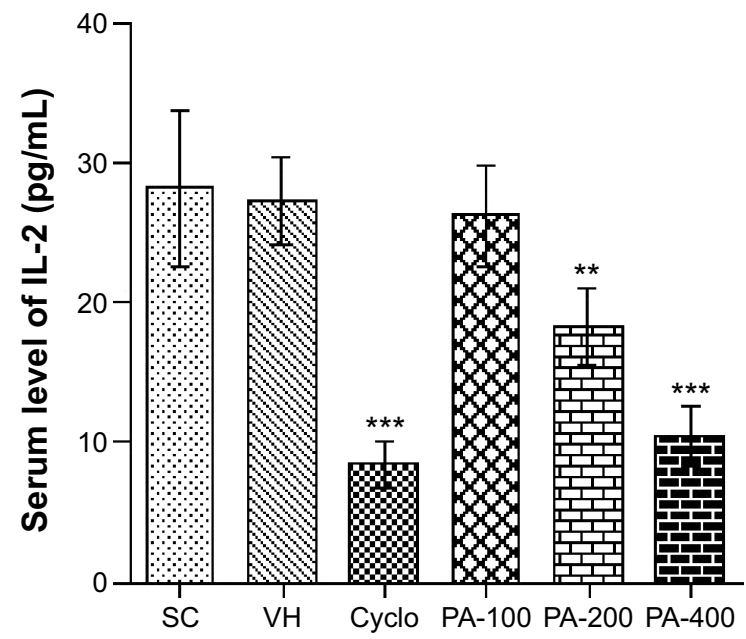

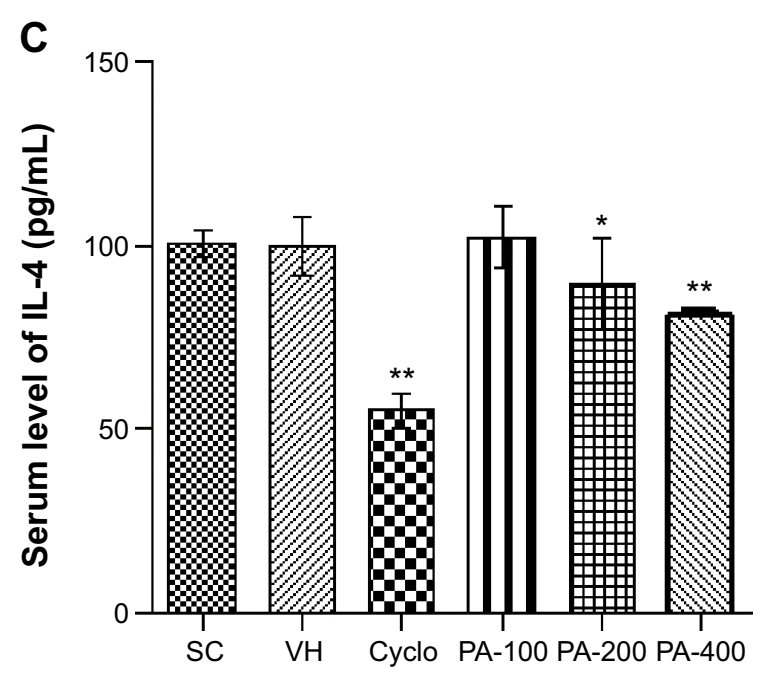

Figure 6 Evaluation of the effect of Phyllanthus amarus (100, 200, $400 \mathrm{mg} / \mathrm{kg}$ ) on IFN- $\gamma$ (A), IL-2 (B), and IL-4 (C) in splenocytes of experimental rats. Notes: Results are represented as mean \pm SEM, with $n=6$ in each group. ${ }^{* * *} \mathrm{P}<0.001 ; * * P<0.01 ; * P<0.05$. The statistical tests employed were ANOVA, followed by postDunnett's test.

Abbreviations: ANOVA, analysis of variance; Cyclo, cyclophosphamide; PA, Phyllanthus amarus; SC, sensitized control; SEM, standard error of the mean; VH, vehicle-treated group; IL-4, interleukin 4; IFN- $\gamma$, interferon $\gamma$.

\section{Discussion}

The immune system is a considerably complex network that plays a vital role protecting the host body from foreign pathogens. The human immune system is a complex network which requires a timely interplay of various immune cell types and crosstalk with the specific tissue microenvironment to maintain immune homeostasis. In this regard, the utilization of several medicinal plants for modulation of the immune system, as an alternative to conventional chemotherapy, in a variety of diseases has prompted increased interest in the field. ${ }^{6}$ The pharmacological activity of a medicinal plant is determined by its chemical nature, composition, and the structure of its major biomarkers. For that reason, the quantitative analysis of biomarker composition in herbal medicines is crucial for quality control and dose determination in the evaluation of toxicological and biological activity. ${ }^{56}$ Therefore, HPLC standardization of $P$. amarus was performed prior to the evaluation of its immunomodulatory potential. In this study, three important bioactive constituents, phyllanthin, hypophyllanthin, and corilagin, were used as chemical markers for standardization. The presence of these lignans and elagitannin in high quantity in the plants could be responsible for its immunomodulatory activity, as described in our previous studies. ${ }^{43,44}$

The present study aimed to investigate the effects of the standardized extract of $P$. amarus on specific and nonspecific immunity parameters, using Wistar-Kyoto rat models. Our previous studies revealed the inhibitory activity of the standardized extract of $P$. amarus and its biomarkers on the in vitro chemotaxis of neutrophils, phagocytosis of $E$. coli by 
human phagocytes, expression of CD11b/CD18 expression in human leukocytes, and production of reactive oxygen species by human leukocytes. ${ }^{43,44}$ Analysis of the data obtained from previous studies showed that extracts of $P$. amarus and its major compounds exert direct pharmacological action on human leukocytes through various mechanisms. ${ }^{43,44}$ Indeed, the data obtained from the current study using the rat model were in line with the results obtained from in vitro assays.

The effect of $P$. amarus extract on Mac-1 expression was studied in ex vivo stimulated neutrophils isolated from treated rats. The regulation of the binding of $\beta 2$ integrin to the ligands plays a pivotal role in leukocyte adhesion to the vascular endothelium, migration of circulating leukocytes to the site of inflammation or injured tissue, and phagocytosis of foreign antigens. Migration of neutrophils has been shown to be mainly regulated by CD18 ( $\beta_{2}$ integrin), as elucidated by previous studies in which the accumulation of neutrophils was suppressed by the addition of blocking monoclonal antibodies. ${ }^{57}$ Exaggerated expression of $\beta_{2}$ integrin CD11b/CD18 (Mac-1), a glycoprotein on the surface of neutrophils, has also been implicated in the development of deleterious systemic inflammatory responses when released into the blood circulation, causing organ damage. ${ }^{58}$ The results obtained from the current study revealed that neutrophils isolated from rats pretreated with extracts at high doses (200 and $400 \mathrm{mg} / \mathrm{kg}$ ) significantly impaired the percentage of CD11b and CD18 expression in neutrophil membrane compared with the control group. This may have resulted from PKC, which is critical in regulation of $\beta_{2}$ integrin. This data may explain the mechanism for the inhibitory activity of $P$. amarus extract in neutrophil-dependent adhesion. The inhibition of CD11b and CD18 expression could also be due to neutrophil proton pump inhibition by $P$. amarus extract. Recent study revealed that suppression of the proton pump can directly inhibit vacuolar (v)-type ATPase, such as Ca ions, which play an essential role in the chemotaxis of neutrophils. ${ }^{56}$ Thus, the reduction in ex vivo fMLP-induced chemotaxis of neutrophils isolated from rats pretreated with the extracts of $P$. amarus could be due to the potential inhibitory effect of $P$. amarus on migration of neutrophils. This could be due to the downregulation of Mac-1, as fMLP has been shown to be involved in stimulation of neutrophils chemotaxis by a mechanism that is mediated by Mac-1..$^{57,59}$

The immunoregulatory effect of $P$. amarus on the phagocytic capacity of neutrophils of treated rats was also investigated. The neutrophil represents a multifunctional cell type in the innate immune response, responsible for clearance of extracellular bacteria via various receptor-dependent mechanisms. The elimination of bacteria by phagocytosis induces the release of cytoplasmic superoxide oxygen in neutrophils, which can subsequently induce apoptosis. The results obtained in this study showed that neutrophils obtained from rats treated with the highest dose of $P$. amarus $(400 \mathrm{mg} / \mathrm{kg})$ exhibited significantly increased inhibitory activity of phagocytosis of E. coli compared with the control group, in ex vivo study. The inhibition of $E$. coli engulfment by neutrophils could be due to the downregulation of CD11b and CD18 expression in neutrophils, as a recent study revealed that antibodies against CR3 are able to suppress the binding of microbes to phagocytes. ${ }^{55}$

The results showed that $P$. amarus-treated and sRBC-sensitized rats mediated a dose-dependent inhibition of both LPS-stimulated B-cell proliferation and ConA-stimulated T-cell proliferation. Investigating the effect of natural products that enhance or suppress lymphocyte inflammatory response acts as an effective means to study immunomodulation and drug discovery. In the present study, the lymphocytes isolated from either treated or nontreated rats were investigated for their cellular immunological responses, due to their critical role in regulating mammalian innate and adaptive immune system, and our results demonstrated that the T and B lymphocytes were differentially activated by the extract at varying doses. The inhibition of lymphocyte proliferation induced by stimuli responsible for $\mathrm{T}$ - and B-cell responses occurred with varying sensitivity, indicating the inhibition of one or more pathways common to $\mathrm{T}$ and $\mathrm{B}$ lymphocyte proliferation.

To further investigate the mechanism of standardized extract of $P$. amarus as an immunosuppressive agent, the effects of standardized extract of $P$. amarus on both $\mathrm{CD}^{+}$and $\mathrm{CD}^{+}$spleen $\mathrm{T}$ lymphocyte populations in sRB-immunized Wistar-Kyoto rats were analyzed by flow cytometric assay. T-cells differentiate into two different subsets that are functionally and phenotypically different, according to their specific membrane molecule. Recent and previous studies demonstrated that both $\mathrm{CD}^{+}$and $\mathrm{CD} 8^{+} \mathrm{T}$-cells are able to modulate immune response through the regulation of cytokines. ${ }^{60}$

Cytokines are hormonal messengers responsible for mediating the migration, activation, and differential proliferation of the cell phenotypes of the immune system. The Th cells are a type of $\mathrm{T}$ lymphocytes that help to augment or potentiate the activity of other immune cells, by releasing T-cell cytokines. Proliferating Th cells are capable of progressing into effector T-cells, which further differentiate into two major, functionally distinct subtypes of cells known as Th1 and Th2 cells. ${ }^{60-62}$ The balance between Th1 and Th2 release of cytokine plays a pivotal role in the determination of direction and outcome of an immune response. Exaggerated release of Th1 cytokine may lead to chronic inflammatory diseases, whereas an abnormal release of the Th2 type is associated to various allergic reactions. The data obtained 
from the study revealed that the extract of $P$. amarus potentially inhibited production of IL-2, IFN- $\gamma$, and IL-4. The inhibition of cytokines produced by Th1 and Th2 cells may be one of the mechanisms behind the downregulation of $\mathrm{T}$ and $\mathrm{B}$ lymphocyte proliferation reported in this study, which proves the potential inhibitory activity of $P$. amarus in T-cell mediated inflammation. Inhibition of $\mathrm{T}$ and $\mathrm{B}$ lymphocytes may have useful application in certain immune-mediated disorders, such as autoimmune disorder and asthma. ${ }^{62}$ The results obtained suggest that the $P$. amarus extract was comparatively better than the standard immunosuppressive drug used in this study, cyclophosphamide, in terms of toxic effect on the body and spleen weight gain.

\section{Conclusion}

Based on the results obtained from this study, it can be concluded that the standardized ethanol extract of $P$. amarus was able to suppress the immune response of both specific and nonspecific immunity in Wistar-Kyoto rats through various pathways. The present study established that the immunosuppressive activity of $80 \%$ ethanol extract of $P$. amarus in Wistar-Kyoto rats exhibited significant inhibition of the phagocytic activity of neutrophils by downregulation of the percentage of $\mathrm{CD} 11 \mathrm{~b}$ and CD18 expression in neutrophils, of chemotaxis, and of phagocytosis of E. coli by neutrophils. In addition, the extract of plant also affected initial and late events of lymphocyte activation, including the release of Th1 and Th2 cytokines, lymphocyte proliferation, as well as the expression of $\mathrm{CD}^{+}$and $\mathrm{CD} 8^{+}$, in splenic lymphocytes. Thus, as an effective immunosuppressive agent, the extract of $P$. amarus may be beneficial for treatment of immune-related disorders and may be a potential immunotherapeutic agent as a substitute for conventional therapeutic agents, which possess toxic effects. However, further molecular based studies are required to elucidate the specific mechanisms behind the immunomodulatory activity of $P$. amarus.

\section{Acknowledgment}

This research is supported by a grant (grant number 02-0102-SF0932) from the Ministry of Science, Technology and Innovation, Malaysia.

\section{Disclosure}

The authors declare no conflicts of interest in this work.

\section{References}

1. Chaplin DD. Overview of the immune response. J Allergy Clin Immunol. 2010;125(2 Suppl 2):S3-S23.

2. Turvey SE, Broide DH. Innate immunity. J Allergy Clin Immunol. 2010;125(2 Suppl 2):S24-S32.

3. Beutler B. Innate immunity: an overview. Mol Immunol. 2004;40(12): $845-859$.
4. Janeway CA Jr, Medzhitov R. Innate immune recognition. Ann Rev Immunol. 2002;20(3):197-216.

5. Medzhitov R, Janeway C Jr. Innate immunity. N Engl J Med. 2000; 343(5):338-344.

6. Vilches C, Parham P. KIR: diverse, rapidly evolving receptors of innate and adaptive immunity. Annu Rev Immunol. 2002;20:217-251.

7. Lee WL, Harrison RE, Grinstein S. Phagocytosis by neutrophils. Microbes Infect. 2003;5(14):1299-1306.

8. Zlotnik A, Yoshie O. Chemokines: a new classification system and their role in immunity. Immunity. 2000;12(2):121-127.

9. Kolaczkowska E, Kubes P. Neutrophil recruitment and function in health and inflammation. Nat Rev Immunol. 2013;13(3):159-175.

10. Michael C. The complement system in regulation of adaptive immunity. Nat Immunol. 2004;5(10):981-986.

11. Rawal N, Rajagopalan R, Salvi VP. Activation of complement component C5: comparison of $\mathrm{C} 5$ convertases of the lectin pathway and the classical pathway of complement. J Biol Chem. 2008;283(12): 7853-7863.

12. Wallis R, Mitchell DA, Schmid R, Schwaeble WJ, Keeble AH. Paths reunited: Initiation of the classical and lectin pathways of complement activation. Immunobiology. 2010;215(1):1-11.

13. Fujita T. Evolution of the lectin-complement pathway and its role in innate immunity. Nat Rev Immunol. 2002;2(5):346-353.

14. Wencker M, Turchinovich G, Di Marco Barros R, et al. Innate-like $\mathrm{T}$ cells straddle innate and adaptive immunity by altering antigenreceptor responsiveness. Nat Immunol. 2014;15(1):80-87.

15. Janeway C, Travers P, Walport M, Shlomchik M. Immunobiology. 5th ed. New York, NY: Garland Publishing; 2001.

16. Diasio RB, LoBuglio AF. Immunomodulators: Immunosuppressive agents and immunostimulants. In: Hardman JG, Limbird LE, Molinoff PB, Ruddon RW, Goodman Gilman A, editors. Goodman and Gilman's The Pharmacological Basis of Therapeutics. 9th ed. New York, NY: McGraw-Hill; 1996:1291-1307.

17. Chew FS, Rodman JE. Plant resources for chemical defense. In: Rosenthal GA, Janzen DH, Applebaum SW, editors. Herbivores: Their Interaction with Secondary Plant Metabolites. New York, NY: Academic Press; 1979:271-307.

18. Alexander CP, Kirubakaran CJ, Michael RD. Water soluble fraction of Tinospora cordifolia leaves enhanced the non-specific immune mechanisms and disease resistance in Oreochromis mossambicus. Fish Shellfish Immunol. 2010;29(5):765-772.

19. Aguilar JL, Rojas P, Marcelo A, et al. Anti-inflammatory activity of two different extracts of Uncaria tomentosa (Rubiaceae). JEthnopharmacol. 2002;81(2):271-276.

20. Anesini C, Werner S, Borda E. Effect of Tilia cordata flower on lymphocyte proliferation: participation of peripheral type benzodiazepine binding sites. Fitoterapia. 1999;70(4):361-367.

21. Sengupta M, Sharma GD, Chakraborty B. Hepatoprotective and immunomodulatory properties of aqueous extract of Curcuma longa in carbon tetra chloride intoxicated Swiss albino mice. Asian Pac J Trop Biomed. 2011;1(3):193-199.

22. Datta S, Sinha S, Bhattacharyya P. Effect of a herbal protein, CI-1, isolated from Cajanus indicus on immune response of control and stressed mice. J Ethnopharmacol. 1999;67(3):259-267.

23. Diallo D, Paulsen BS, Liljebäck TH, Michaelsen TE. Polysaccharides from the roots of Entada africana Guill. et Perr., Mimosaceae, with complement fixing activity. J Ethnopharmacol. 2001;74(2): 159-171.

24. Yesilada E, Bedir E, Caliş I, Takaishi Y, Ohmoto Y. Effects of triterpene saponins from Astragalus species on in vitro cytokine release. J Ethnopharmacol. 2005;96(1-2):71-77.

25. Qin F, Sun HX. Immunosuppressive activity of Pollen Typhae ethanol extract on the immune responses in mice. $J$ Ethnopharmacol. 2005;102(3):424-429.

26. Bin-Hafeez B, Haque R, Parvez S, Pandey D, Sayeed I, Raisuddin S. Immunomodulatory effects of fenugreek (Trigonella foenum graecum L.) extract in mice. Int Immunopharmacol. 2003;3(2):257-265. 
27. Sun HX, Qin F, Pan YJ. In vitro and in vivo immunosuppressive activity of Spica Prunellae ethanol extract on the immune responses in mice. J Ethnopharmacol. 2005;101(1-3):31-36.

28. Jantan I, Harun NH, Septama AW, Murad S, Mesaik MA. Inhibition of chemiluminescence and chemotactic activity of phagocytes in vitro by the extracts of selected medicinal plants. J Nat Med. 2011;65(2): 400-405.

29. Fakeye TO, Pal A, Bawankule DU, Khanuja SP. Immunomodulatory effect of extracts of Hibiscus sabdariffa L. (Family Malvaceae) in a mouse model. Phytother Res. 2008;22(5):664-668.

30. Jayathirtha MG, Mishra SH. Preliminary immunomodulatory activities of methanol extracts of Eclipta alba and Centella asiatica. Phytomedicine. 2004;11(4):361-365.

31. Khan S, Malik F, Suri KA, Singh J. Molecular insight into the immune up-regulatory properties of the leaf extract of Ashwagandha and identification of Th1 immunostimulatory chemical entity. Vaccine. 2009; 27(43):6080-6087.

32. Gautam M, Diwanay S, Gairola S, Shinde Y, Patki P, Patwardhan B. Immunoadjuvant potential of Asparagus racemosus aqueous extract in experimental system. J Ethnopharmacol. 2004;91(2-3):251-255.

33. Manjrekar PN, Jolly CI, Narayanan S. Comparative studies of the immunomodulatory activity of Tinospora cordifolia and Tinospora sinensis. Fitoterapia. 2000;71(3):254-257.

34. Manosroi A, Saraphanchotiwitthaya A, Manosroi J. In vivo immunomodulating activity of wood extracts from Clausena excavata Burm $\mathrm{f}$. J Ethnopharmacol. 2005;102(1):5-9.

35. Millonig RC, Amrein BJ, Kirschbaum J, Hess SM. Immunosuppressive and antiinflammatory activities of cinanserin and its analogs. $\mathrm{J} \mathrm{Med}$ Chem. 1974;17(7):772-775.

36. Gracious Ross R, Selvasubramanian S, Jayasunder S. Immunomodulatory activity of Punica granatum in rabbits - a preliminary study. J Ethnopharmacol. 2001;78(1):85-87.

37. Scaglione F, Ferrara F, Dugnani S, Falchi M, Santoro G, Fraschini F. Immunomodulatory effects of two extracts of Panax ginseng C.A. Meyer. Drugs Exp Clin Res. 1990;16(10):537-542.

38. Shukla S, Mehta A, Kim M, Ayyadurai N. In vivo immunomodulating activities of ethanolic leaf extract of Stevia rebaudiana in albino rats. Res J Biotechnol. 2011;6(1):27-31.

39. Singh D, Aggarwal A, Mathias A, Naik S. Immunomodulatory activity of Semecarpus anacardium extract in mononuclear cells of normal individuals and rheumatoid arthritis patients. $J$ Ethnopharmacol. 2006;108(3):398-406

40. Foo LY. Amarulone, a novel cyclic hydrolysable tannin from Phyllanthus amarus. Natural Prod Lett. 1993;3(1):45-52.

41. Shokunbi OS, Odotela AA. Gastroprotective and antioxidant activities of Phyllanthus amarus extracts on absolute ethanol-induced ulcer in

42. Patel JR, Tripathi P, Sharma V, Chauhan NS, Dixit VK. Phyllanthus a review. J Ethnopharmacol. 2011;138(2):286-313.

43. Kassuya CA, Leite DF, de Melo LV, Rehder VL, Calixto JB. Antiinflammatory properties of extracts, fractions and lignans isolated from Phyllanthus amarus. Planta Med. 2005;71(8):721-726.

44. Jantan I, Ilangkovan M, Mohamad Y, Mohamad HF. Correlation between the major components of Phyllanthus amarus and Phyllanthus urinaria and their inhibitory effects on phagocytic activity of human neutrophils. BMC Complement Altern Med. 2014;14:429. albino rats. J Med Plants Res. 2008;2(10):261-267. amarus: ethnomedicinal uses, phytochemistry and pharmacology:

45. Yuandani, Ilangkovan M, Jantan I, Mohamad HF, Husain K, Abdul Razak AF. Inhibitory effects of standardized extracts of Phyllanthus amarus and Phyllanthus urinaria and their marker compounds on phagocytic activity of human neutrophils. Evid Based Complement Alternat Med. 2013;2013:603634.

46. OECD [Organisation for Economic Co-operation and Development]. Guidance document on the recognition, assessment, and use of clinical signs as humane endpoints for experimental animals used in safety evaluation. Paris: OECD; 2000. Available from: http://www.oecd. org/officialdocuments/publicdisplaydocumentpdf/?cote=env/jm/ mono(2000)7\&doclanguage $=$ en. Accessed March 21, 2015.

47. Karuna R, Reddy SS, Baskar R, Saralakumari D. Antioxidant potential of aqueous extract of Phyllanthus amarus in rats. Indian J Pharmacol. 2009;41(2):64-67.

48. Tian F, Li B, Ji B, et al. Antioxidant and antimicrobial activities of consecutive extracts from Galla chinensis: The polarity affects the bioactivities. Food Chem. 2009;113(1):173-179.

49. Zhang Z, Li D, Wang L, et al. Optimization of ethanol-water extraction of lignans from flaxseed. Sep Purif Technol. 2007;57(1):17-24.

50. Kumar S, Jyoti A, Keshari RS, Singh M, Barthwal MK, Dikshit M. Functional and molecular characterization of NOS isoforms in rat neutrophil precursor cells. Cytometry A. 2010;77(5):467-477.

51. Wang C, Yu X, Cao Q, et al. Characterization of murine macrophages from bone marrow, spleen and peritoneum. BMC Immunol. 2013;14:6.

52. Colić M, Vucević D, Kilibarda V, Radicević N, Savić M. Modulatory effects of garlic extracts on proliferation of T-lymphocytes in vitro stimulated with concanavalin A. Phytomedicine. 2002;9(2):117-124.

53. Gupta A, Khajuria A, Singh J, et al. Immunomodulatory activity of biopolymeric fraction RLJ-NE-205 from Picrorhiza kurroa. Int Immunopharmacol. 2006;6(10):1543-1549.

54. Chauhan PS, Gupta KK, Bani S. The immunosuppressive effects of Agyrolobium roseum and pinitol in experimental animals. Int Immunopharmacol. 2011;11(2):286-291.

55. Hofman P, Piche M, Far DF, et al. Increased Escherichia coli phagocytosis in neutrophils that have transmigrated across a cultured intestinal epithelium. Infect Immun. 2000;68(2):449-455.

56. Yoshida N, Yoshikawa T, Tanaka Y, et al. A new mechanism for antiinflammatory actions of proton pump inhibitors - inhibitory effects on neutrophil-endothelial cell interactions. Aliment Pharmacol Ther. 2000;14 Suppl 1:S74-S81.

57. Coxon A, Rieu P, Barkalow FJ, et al. A novel role for the beta 2 integrin CD11b/CD18 in neutrophil apoptosis: a homeostatic mechanism in inflammation. Immunity. 1996;5(6):653-666.

58. Loike JD, Cao L, Budhu S, et al. Differential regulation of beta1 integrins by chemoattractants regulates neutrophil migration through fibrin. J Cell Biol. 1999;144(5):1047-1056.

59. Ley K, Laudanna C, Cybulsky MI, Nourshargh S. Getting to the site of inflammation: the leukocyte adhesion cascade updated. Nat Rev Immunol. 2007;7(9):678-689.

60. Luckheeram RV, Zhou R, Verma AV, Xia B. CD4 ${ }^{+}$T cells: differentiation and functions. Clin Dev Immunol. 2012;2012:925135.

61. Mosmann TR, Sad S. The expanding universe of T-cell subsets: Th1, Th2 and more. Immunol Today. 1996;17(3):138-146.

62. Farrar JD, Asnagli H, Murphy KM. T helper subset development: roles of instruction, selection, and transcription. J Clin Invest. 2002;109(4): $431-435$.

\section{Dovepress}

\section{Publish your work in this journal}

Drug Design, Development and Therapy is an international, peerreviewed open-access journal that spans the spectrum of drug design and development through to clinical applications. Clinical outcomes, patient safety, and programs for the development and effective, safe, and sustained use of medicines are a feature of the journal, which

has also been accepted for indexing on PubMed Central. The manuscript management system is completely online and includes a very quick and fair peer-review system, which is all easy to use. Visit http://www.dovepress.com/testimonials.php to read real quotes from published authors. 